\title{
Using MM5 to Hindcast the Ocean Surface Forcing Fields over the Gulf of Maine and Georges Bank Region*
}

\author{
Changsheng Chen \\ School for Marine Science and Technology, University of Massachusetts_Dartmouth, New Bedford, Massachusetts \\ R. C. BEARDSLEy \\ Department of Physical Oceanography, Woods Hole Oceanographic Institution, Woods Hole, Massachusetts \\ Song Hu AND Qichun Xu \\ School for Marine Science and Technology, University of Massachusetts—Dartmouth, New Bedford, Massachusetts \\ HUICHAN LiN \\ Department of Marine Science, University of Georgia, Athens, Georgia
}

(Manuscript received 4 March 2004, in final form 18 June 2004)

\begin{abstract}
The fifth-generation Pennsylvania State University-NCAR Mesoscale Model (MM5) is applied to the Gulf of Maine/Georges Bank (GoM/GB) region. This model is configured with two numerical domains with horizontal resolutions of 30 and $10 \mathrm{~km}$, respectively, and driven by the NCAR-Eta weather model through a nested grid approach. Comparison of model-computed winds, wind stress, and heat flux with in situ data collected on moored meteorological buoys in the western GoM and over GB in 1995 shows that during the passage of atmospheric fronts over this region, MM5 provides a reasonable prediction of wind speed but not wind direction, and provides a relatively accurate estimation of longwave radiation but overestimates sensible and latent fluxes. The nudging data assimilation approach with inclusion of in situ wind data significantly improves the accuracy of the predicted wind speed and direction. Incorporation of the Fairall et al. air-sea flux algorithms with inclusion of Advanced Very High Resolution Radiometer (AVHRR)derived SST improves the accuracy of the predicted latent and sensible heat fluxes in the GoM/GB region for both stable and unstable weather conditions.
\end{abstract}

\section{Introduction}

One of major goals of the U.S. Global Ocean Ecosystem (GLOBEC) Northwest Atlantic/Georges Bank program is to simulate the seasonal variation of stratification and subtidal circulation in the Gulf of Maine/ Georges Bank (GoM/GB) region. To achieve this goal, we need a mesoscale meteorological model that is capable of providing accurate, high-resolution fields of the surface wind stress and heat flux. The fifth-

\footnotetext{
* Global Ocean Ecosystem Dynamics (GLOBEC)/Georges Bank Program Contribution Number 437.
}

Corresponding author address: Changsheng Chen, School for Marine Science and Technology, University of MassachusettsDartmouth, New Bedford, MA 02742.

E-mail: c1chen@umassd.edu generation Mesoscale Model (MM5) was selected for this purpose. MM5 is a regional nonhydrostatic, terrainfollowing, sigma-coordinate weather model developed jointly by the National Center for Atmospheric Research (NCAR) and Pennsylvania State University (PSU) (Dudhia et al. 2003). This model was developed originally by R. A. Anthes and his colleagues at PSU in the early 1970s (Anthes and Warner 1978) and modified by NCAR and PSU modelers to include a multiplenesting capability, nonhydrostatic dynamics, and fourdimensional data assimilation capability (Grell et al. 1994). The MM5 has been widely used for local weather forecasting and has recently come to the attention of the coastal ocean modeling community, who want to have accurate sea surface boundary forcing fields to drive forecast, nowcast, or hindcast coastal ocean models for both practical and scientific applications.

Many efforts have been made to improve the capability of simulating or assimilating the dynamics of the 
planetary boundary layer (PBL) in MM5 (Zhang and Anthes 1982; Holtslag and Nieuwstadt 1986; Zhang et al. 1986; Genon 1987; Burk and Thompson 1989; Noilhan and Planton 1989; Jacquemin and Noilhan 1990; Pleim and Chang 1992; Dudhia 1993; Grell 1993; Janjic 1994; Pleim and Xiu 1995; Zou et al. 1995). The availability of different PBL numerical schemes in MM5 has provided a solid scientific tool for studying mesoscale convective processes, air-frontal dynamics, land-sea breezes, etc. (Dudhia et al. 2003). Since MM5 has been developed primarily to meet requirements for weather forecasting over land, relatively little effort has been made to validate this model regarding the accuracy of the predicted meteorological conditions and momentum and heat fluxes at the ocean surface. MM5 is normally run with a high-resolution PBL scheme for heat flux estimation at the model's bottom surface (over both land and ocean). Since variation of the net heat flux is very sensitive to parameterizations of the sensible and latent fluxes (Webster and Lukas 1992), it is questionable whether or not the parameterizations chosen in MM5 could provide accurate estimation of the heat flux at the sea surface.

As one component of the U.S. GLOBEC Northwest Atlantic/GB program, a Woods Hole Oceanographic Institution (WHOI) surface buoy supporting both meteorological and oceanographic instrumentation was moored at a midshelf site on the southern flank of GB in 1995 (Beardsley et al. 2003) (Fig. 1). The wind speed and direction, air and sea surface temperatures, relative humidity, incident shortwave and longwave radiation, barometric pressure, and precipitation were recorded from 1 February to 23 August to monitor surface weather conditions and provide accurate estimation of the surface momentum (wind stress), heat, and water fluxes during the 1995 Stratification Study. These direct measurements and flux estimates plus wind data collected on existing NOAA environmental buoys (Fig. 1) provide an opportunity to test and validate MM5 in its application to the GoM/GB region.

Our MM5 numerical experiments were conducted through a nesting approach from a regional domain (with $30-\mathrm{km}$ grid resolution) to a local GoM/GB domain (with 10-km grid resolution) for 1995 during which the GLOBEC measurements on the southern flank of GB were available (Fig. 1). Initial model-data comparisons indicated that during atmospheric frontal passages, MM5 provides a reasonable prediction of wind speed but not direction and estimates with reasonable accuracy the net longwave radiation heat flux but overestimates both sensible and latent heat fluxes. An internal MM5 nudging data assimilation method was then turned on to merge the model-predicted and buoy-based surface wind fields. The surface sensible and latent heat flux equations in MM5 were also replaced by the bulk air-sea flux algorithms developed by Fairall et al. (1996). The modified MM5 with inclusion of the daily satellite-derived sea surface temperature

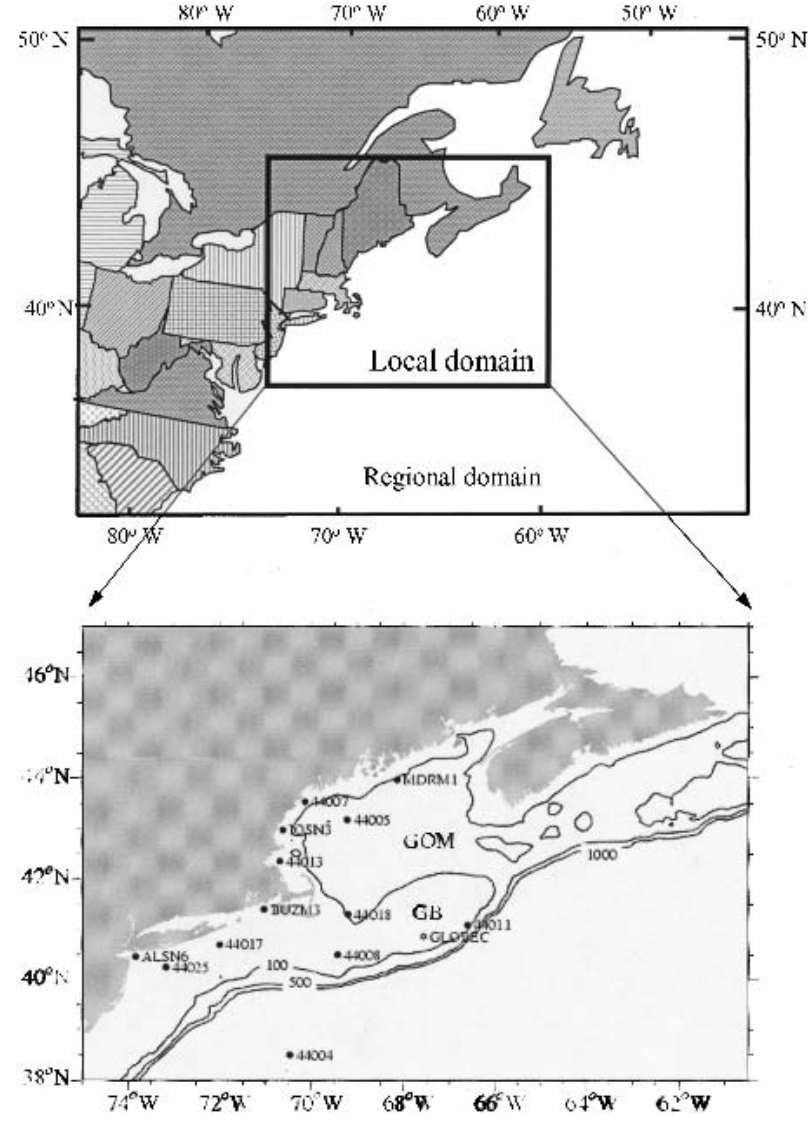

FIG. 1. (top) Regional and (bottom) local domains used in the Gulf of Maine/Georges Bank MM5 model. The locations and names of coastal meteorological buoys that provided data within the local domain to this study are shown by the solid dots. The star on the southern flank of Georges Bank indicates the position of the U.S. GLOBEC meteorological buoy, which provided time series of wind stress and heat flux for the study period. The 100-, 500-, and 1000-m isobaths are shown; GOM: the Gulf of Maine and GB: Georges Bank.

field produced more accurate sensible and latent surface heat fluxes during atmospheric frontal passages.

The remaining sections of this paper are organized as follows. In section 2, the design of the numerical experiments is described. In section 3 , comparisons between MM5-predicted and observed 10-m wind velocity and surface heat fluxes are presented. In section 4, the Fairall et al. (1996) bulk air-sea flux algorithms are put into MM5, and the resulting model surface heat fluxes are compared with the GLOBEC measurements. Discussions and a summary are given in section 5 .

\section{Design of numerical experiments}

The nonhydrostatic version of MM5 is used in this study. To resolve synoptic-scale weather systems, the GoM/GB MM5 is configured with regional and local computational domains with horizontal resolutions of 
30 and $10 \mathrm{~km}$, respectively (Fig. 1). The regional domain consists of $101 \times 69$ grid points, and the local domain includes $130 \times 103$ grid points. A pressuredefined $\sigma$-coordinate transformation is used in the vertical. This is a terrain-following system in which $\sigma$ levels follow the terrain near the bottom, gradually flattening as the pressure decreases, and remain flat in the upper atmosphere. A total of $31 \sigma$ levels were specified for both regional and local domains and the thickness of each layer depends on the reference-state pressure, finer in the surface boundary layer than in the upper atmosphere. The thickness of the surface layer is $20 \mathrm{~m}$. This specification is consistent with the suggestion made by Zhang and Wang (2003). Based on their experiments, they argued that a thin surface layer (about $20 \mathrm{~m}$ ) is required to provide realistic simulation of the surface wind.

In this study, MM5 is initialized using the National Centers for Environmental Prediction (NCEP) reanalysis (with a horizontal resolution of $2.5^{\circ}$ ) or NCEP's Eta (40-km resolution) databases, with a preference for the latter when it was available. The regional and local domains were run simultaneously through "two-way interaction." Two-way interaction is a nesting method in which the input from the coarse mesh is included via boundaries and feedback to the coarse mesh covers the entire nested interior (Zhang et al. 1986). The model was run for an integration period of every 3.5 days with 12 hours of model spinup time, starting on 1 January 1995. The initial and boundary conditions for a 3.5-day run were specified using the NCEP reanalysis or Eta databases. In particular, the model began running at 1200 UTC 31 December 1994 and was integrated until 0000 UTC 4 January 1995, with a 12-h ramp from the starting time. The model results were output with an hourly time interval from 0000 UTC 1 January to 0000 UTC 4 January, a 3-day period. The model was then restarted at 1200 UTC 3 January, 12 hours backward from the end of the previous integration, and run for an additional 3.5 days with a 12-h ramp from 1200 UTC 3 January to 0000 UTC 4 January. The model results were then output from 0100 UTC 4 January to 0000 UTC 6 January. This process was repeated every 3.5 days with an overlapping of 12 hours to produce continuous model simulation results with an hourly time interval for the rest of the year. The time step used in integration was 90 s for the regional domain and 30s for the local domain.

MM5 includes a four-dimensional nudging data assimilation approach to merge the model-predicted physical variables and parameters to the real-time observations taken by aircraft, weather balloons, satellite, and the network of land stations. Analysis nudging was applied to domain 1 (coarse grid) and observation nudging to domain 2 (fine grid). To investigate the accuracy of MM5 in the GoM/GB region, two types of numerical experiments were conducted. The first is referred to as a "simulation case" in which no ocean buoy data were included in the nudging, while the second is called an "assimilation case" in which model-computed wind velocities were nudged to merge with all ocean buoy data available within the local domain. The terms "simulation" and "assimilation" are used here to distinguish the experimental setup for the ocean, with the understanding that all available land observations are assimilated in both cases. Running MM5 in the simulation and assimilation modes will allow us to assess the importance of including ocean surface measurements in the model prediction over the coastal ocean.

It is widely recognized that the planetary boundary layer plays a critical role in mesoscale weather variability (Zhang and Anthes 1982). Since the dynamic features of mesoscale motion are so complex, most PBL models depend on boundary parameterizations. There are a variety of PBL models available in MM5, which include 1) Bulk PBL, 2) Blackadar PBL, 3) BurkThompson PBL, 4) Eta PBL, 5) Medium-Range Forecast (MRF) (Hong-Pam) PBL, 6) Gayno-Seaman PBL, and 7) Pleim-Change PBL. According to the MM5 users' guide (Dudhia et al. 2003), with the sole exception of Bulk PBL, the other PBL models are designed to represent turbulent mixing due to 1) vertical diffusion represented by an eddy exchange coefficient $K$ and 2) free and forced convection in unstable weather conditions.

The primary differences between these PBL models are the parameterizations used for these two mixing processes. For example, diffusive and convective mixing are parameterized with a nocturnal module depending on the $\mathrm{K}$ theory and a free-convection module depending on the ratio of the height of mixed layer to the Monin-Obukhov length in the Blackadar PBL model (Blackadar 1976, 1979; Zhang and Anthes 1982), while they are calculated using the Mellor and Yamada PBL formulation with a Betts and Miller cumulus parameterization in the Eta PBL model (Mellor and Yamada 1974, 1982; Betts and Miller 1986; Janjic 1994). The MRF PBL model uses a nonlocal vertical diffusion scheme based on Troen and Mahrt (1986), in which surface fluxes, turbulent diffusion, and boundary layer depth are parameterized in terms of similarity theory, bulk similarity, and a bulk Richardson number, respectively. This model is computationally efficient and has a slight bias toward prediction of the growth of the convectively mixed layer and surface heat flux during the transition between stable and unstable weather conditions (Hong and Pan 1996).

Selection of these PBL models depends highly on the user's experience. To our knowledge, little attention has been paid to the accuracy of available MM5 PBL models on estimating the heat flux at the coastal ocean surface, though efforts have been made to examine the influence of PBL model parameterizations on the intensity of hurricanes (Braun and Tao 2000) and the diurnal cycle of surface winds related to surface temperature fluctuations (Zhang and Zheng 2004). To ex- 
amine the sensitivity of model-computed surface wind velocity and heat flux to the choice of PBL model, we ran MM5 for the GoM/GB region with the Blackadar, ETA, MRF, and Gayno-Seaman PBL models and compared the results with the 1995 field data. The BettsMiller convective parameterization scheme is generally appropriate for the case with a grid size larger than 30 $\mathrm{km}$, and the Grell convective parameterization scheme is suitable for the case with a grid size of 10-30 km (Grell 1993). In our experiments, the Grell scheme was used for all cases.

Fairall et al. (1996) developed a bulk air-sea heat flux algorithm based on Monin-Obukhov similarity theory with modifications for the roughness-stress relationship, boundary-layer-scale gustiness velocity and convective limit. This algorithm (called here the TC algorithm) was used successfully by Fairall et al. (1996) to accurately estimate the surface heat flux in the Tropical Ocean and Global Atmosphere (TOGA) program and Coupled Ocean-Atmosphere Response Experiment (COARE), and used by Beardsley et al. (2003) to estimate the surface heat flux at the GLOBEC buoy site on the southern flank of GB. Since the TC bulk algorithm is known to compare well with direct turbulent flux measurements made over the open ocean and is in common use in coastal ocean research, we modified MM5 to include the TC algorithm as an option to the current MM5 air-sea flux algorithms.

In situ field data used in this study include 1) hourly recorded wind speeds and directions measured on the 14 coastal buoys shown in Fig. 1,2) time series of the surface heat flux estimated at the GLOBEC southern flank GB buoy site, and 3) declouded Advanced Very High Resolution Radiometer (AVHRR)-derived sea surface temperature (SST). The buoy wind data and SST image data were directly downloaded from the NOAA Data Center and Jet Propulsion Laboratory (JPL) public data Web sites. The GLOBEC heat flux estimations were made using the TC algorithm, as described in Pawlowicz et al. (2001).

\section{Results of the MM5 simulation experiment}

The MM5 simulation run was made for 1 January-28 February 1995. With no assimilation of buoy wind data, the accuracy of the surface $10-\mathrm{m}$ wind velocity predicted by MM5 at the buoys depended on the weather conditions. MM5 did better in stable weather conditions but made larger errors in wind direction during atmospheric frontal passages. For example, during 3-9 February 1995, a period of low pressure cold-air frontal passage, MM5-predicted wind speeds were in good agreement with buoy wind speeds, but the predicted directions tended to vary too smoothly and deviate from the buoy wind directions (Fig. 2). The bias in wind direction was more severe around the center of the low pressure system when the front moved over the ocean

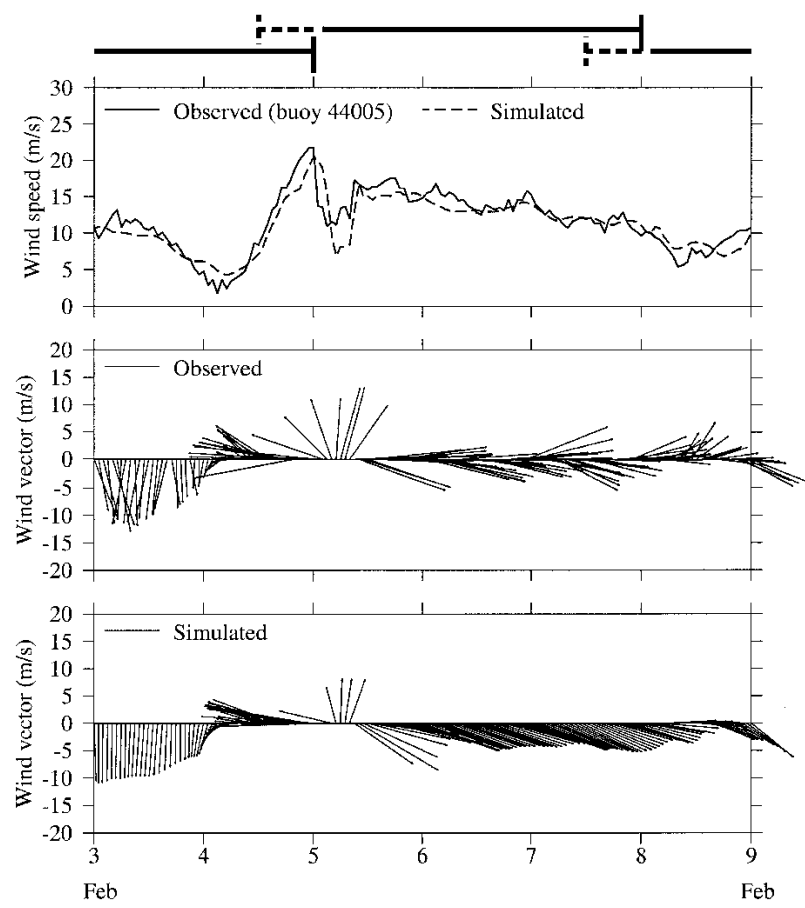

FIG. 2. Comparison of model-simulated and observed wind speed and wind vectors at a height of $10 \mathrm{~m}$ above the sea surface on buoy 44005 for the period 3-9 Feb 1995. In this simulation case, coastal buoy winds were not included. Heavy solid line: the model integration period with the output as model results; heavy dashed line: the 12-h spinup period for each 3.5-day simulation.

(Fig. 3). It appears that the predicted frontal system moved faster than observed when it crossed over the ocean (Fig. 3). This is probably one of the reasons that the MM5-predicted wind directions did not match the buoy measurements well. The results shown in Figs. 2 and 3 were produced using the MRF PBL model; however, the other PBL models tested produced the same tendencies for erring more in wind direction than speed.

The accuracy of the MM5-predicted surface heat flux also strongly depended on weather conditions. When the cloud-free AVHRR-derived SST time series was included in the simulation run, MM5 tended to overestimate the surface sensible and latent heat fluxes during unstable weather conditions. For example, during the 3-9 February cold-air frontal passage, surface sensible and latent fluxes predicted by MM5 with MRF PBL were in good agreement with the GLOBEC buoy estimates before 5 February before the cold frontal passage but were much too large during 5-7 February, after the center of the low had passed (Fig. 4). The GLOBEC buoy sensible and latent heat fluxes were about $200 \mathrm{~W}$ $\mathrm{m}^{-2}$ during 6-7 February, but the MM5-predicted values during that period exceeded $500 \mathrm{~W} \mathrm{~m}^{-2}$, more than $300 \mathrm{~W} \mathrm{~m}^{-2}(>100 \%)$ larger than the true value.

Using different PBL models in MM5 made some differences in predicted air-sea fluxes (Fig. 4). Prior to the 

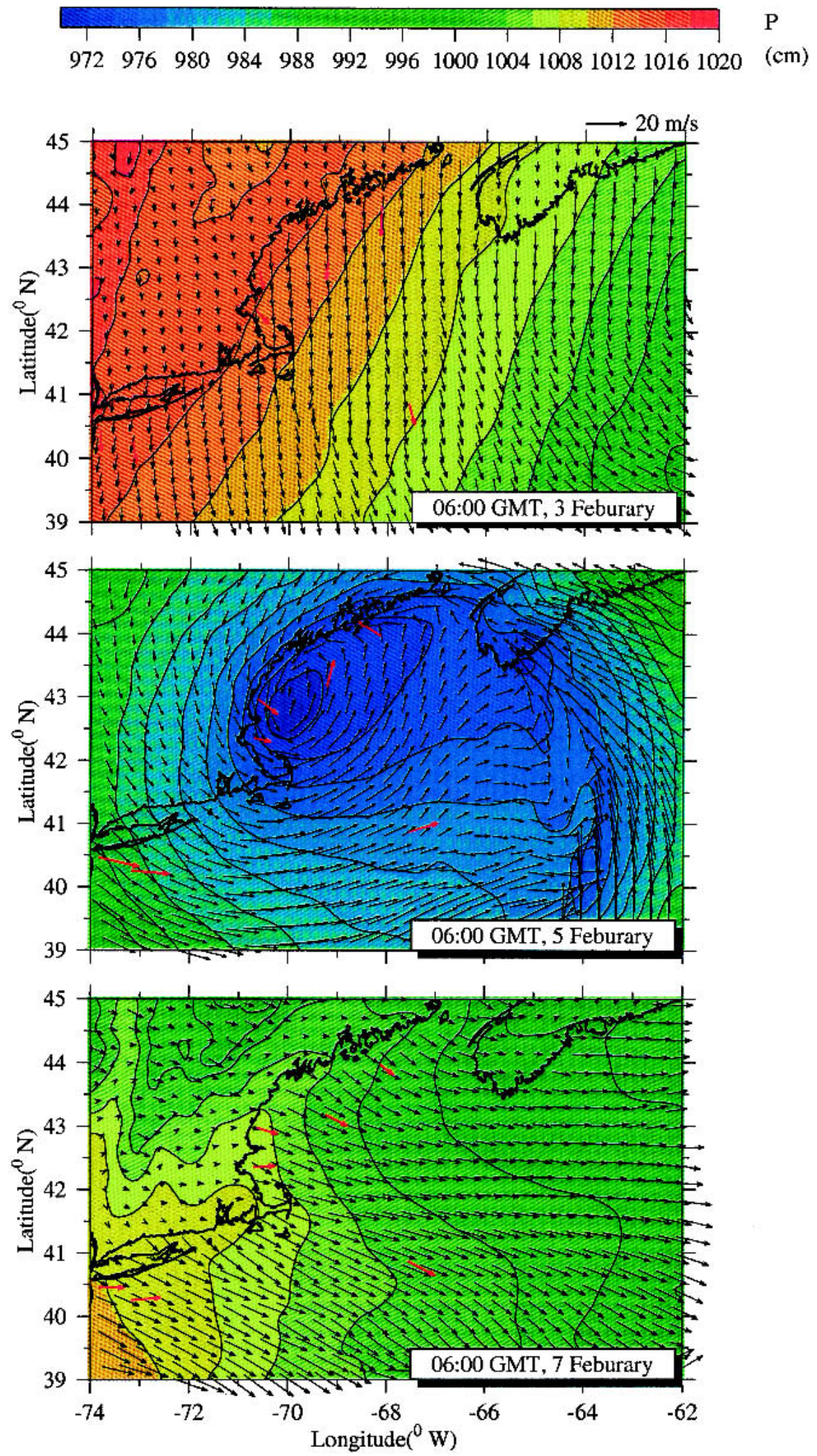

FIG. 3. Model-simulated $10-\mathrm{m}$ wind vectors (black) and surface air pressure (color contours) at 0600 UTC 3, 5, and 7 Feb 1995. The red vectors show the 10-m vector winds measured on the coastal buoys. 

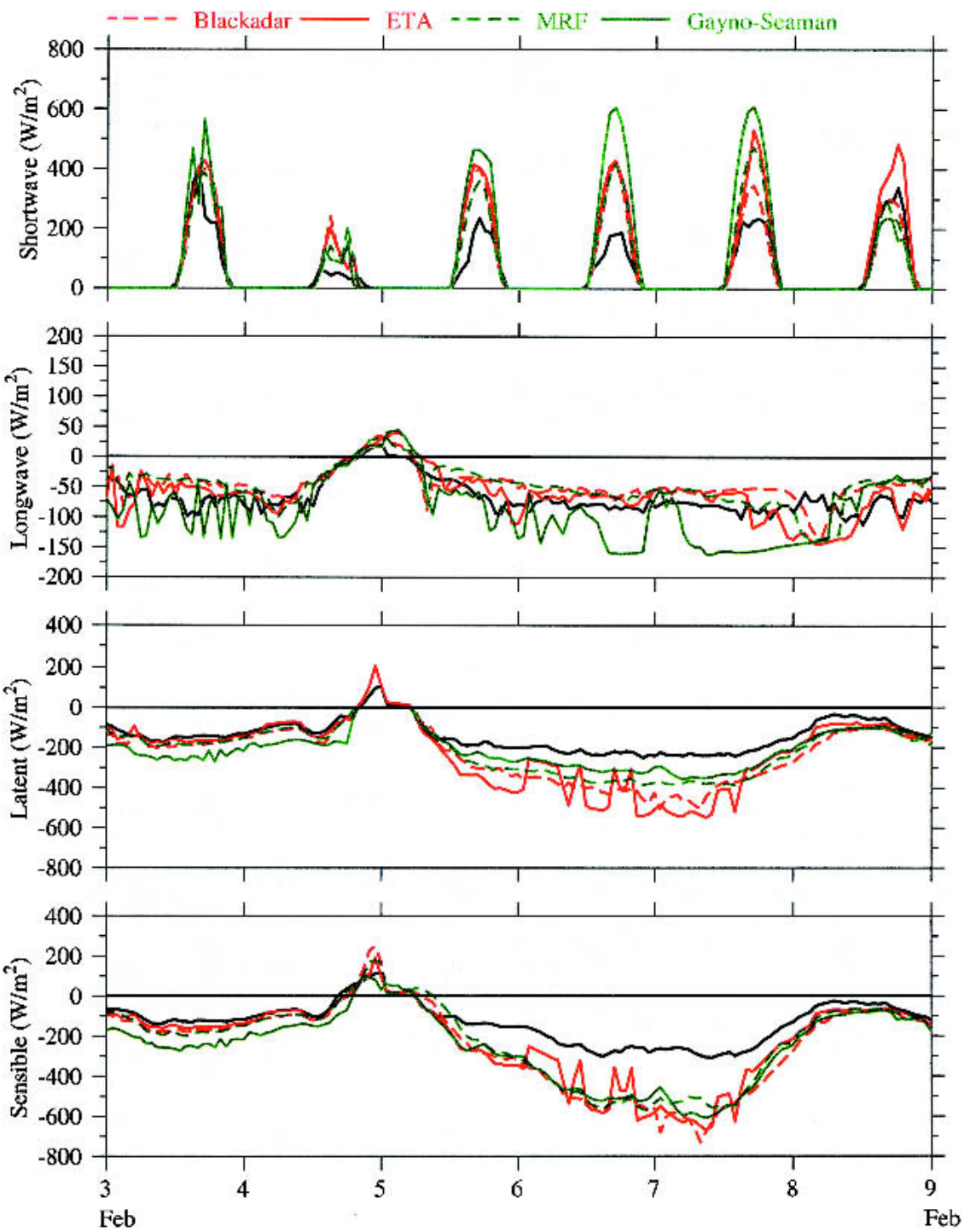

FIG. 4. Time series of the net shortwave radiation, longwave radiation, and latent and sensible heat fluxes simulated at the GLOBEC buoy site on the southern flank of GB with the Blackadar, ETA, MRF, and Gayno-Seaman PBL models for the 3-9 Feb period. The buoyderived fluxes are shown by the heavy solid black curves.

cold frontal passage, the Blackadar and ETA PBL model sensible flux predictions agreed better with the buoy values than the MRF and Gayno-Seaman PBL models; however, after the low center passage on 5 February, all four models did a similarly poor job (Table 3). Before the low passage, the Blackadar, ETA, and MRF PBL model latent flux predictions agreed well with the buoy estimate; however, after the low passage, the Blackadar and ETA PBL models overpredicted latent flux more than the other two models. The GaynoSeaman PBL model produced the best latent flux prediction after the passage of the low pressure center. However, it was still considerably larger than the buoy value. This model also overpredicted both latent and sensible fluxes during the stable conditions before the low pressure center arrived at the GLOBEC mooring site. The ETA PBL model showed large (of order 100

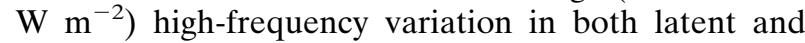
sensible fluxes during the cold frontal passage that did not appear in the other PBL model results or in the buoy time series. The Blackadar, ETA, and MRF PBL models produced a relative accurate prediction for the net longwave radiation flux at the sea surface, but the Gayno-Seaman PBL model did not (Fig. 4, second panel). In the PBL model experiments, the longwave upward flux was estimated by SST, while the downward flux depends on a radiometric sky temperature. The failure of the Gayno-Seaman scheme to simulate accurately a net longwave flux suggests that the method used to estimate the radiometric sky temperature in this 
scheme needs to be improved for unstable weather conditions. The improvement is also required for the estimation of downward shortwave radiation since the four PBL models used in our experiments all overpredicted the net shortwave radiation flux by various amounts on different days.

The simulation experiments indicate that the daily variation of the sea surface water temperature cannot be ignored in the air-sea heat flux estimation in the MM5 PBL model.

An example can be seen in Fig. 5, which presents a comparison between the MRF PBL model-predicted latent and sensible heat fluxes for the cases with a constant sea surface temperature (the original setup in MM5) and with inclusion of the daily AVHRR-derived SST. Here the constant sea surface temperature refers to the average temperature of SST (with a horizontal resolution of $2.5^{\circ}$ ) over the period of integration. The daily SST was constructed from a digital image dataset with a horizontal resolution of $9 \mathrm{~km}$. In this comparison, the model prediction including daily SST data reduced the overestimation of latent and sensible fluxes by as much as $100-150 \mathrm{~W} \mathrm{~m}^{-2}$, which is a significant fraction of the net heat flux.

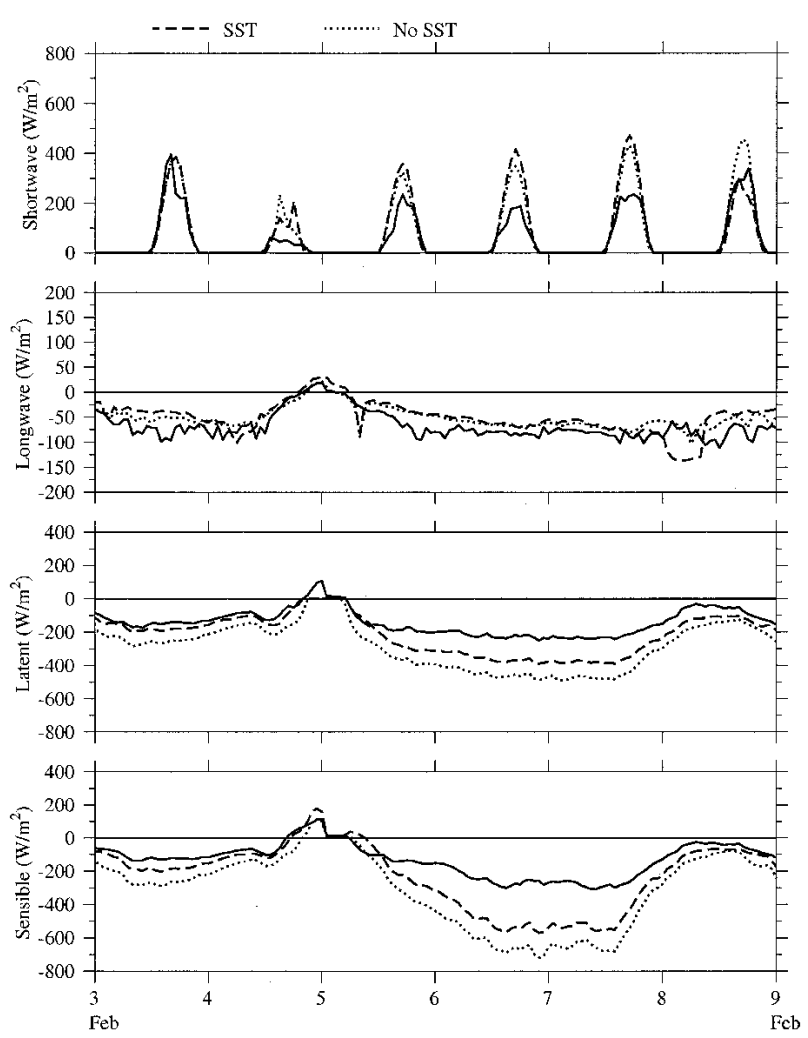

FIG. 5. Time series of the net shortwave radiation, longwave radiation, and latent and sensible heat fluxes simulated at the GLOBEC buoy site with the MRF PBL model with and without inclusion of the AVHHR-derived SST. The buoy-derived fluxes are shown by the heavy solid black curves.

\section{Results of the MM5 assimilation experiments}

Synoptic weather systems generally approach the GoM/GB region from the northwest (over the continent) in winter through spring and from the southwest (along the U.S. southeast coast) in summer. Since the available meteorological buoys in the GoM/GB region and the Mid-Atlantic Bight (MAB) shown in Fig. 1 are distributed along the northeastern coast and southwestern part of the ocean, they could act like a controller for MM5 in its application to the GoM/GB region. The station nudging data assimilation method in MM5 was turned on to merge the predicted wind velocity to the hourly wind velocity measured at each buoy in the local computational domain. The parameters such as influence radius, time window, relaxation time scale, and nudging coefficient were specified according to an overall standard deviation judgment on best merging the wind speed and direction on individual stations and minimizing the adjustment of the distribution of the mesoscale and synoptic pressure fields as well as numerical stability. In this study, the nudging formulation was parameterized with a horizontal influence radius of $100 \mathrm{~km}$, a vertical influence radius of $0.001 \sigma$-unit, a time window of $40 \mathrm{~min}$, and a relaxation time scale of 60 min. A nudging coefficient of $1 \times 10^{-2}$ was used, which was much larger than the local Coriolis parameter $\left(10^{-4}\right)$ recommended in the MM5 manual.

This station nudging approach using all the buoy wind data successfully tuned the model-predicted winds in the GoM/GB region (Tables 1 and 2). For example, NOAA Buoy 44005 showed a maximum wind speed directed toward the southwest at midnight on 4 February. This wind speed peak occurred one hour later in the simulation run but on time in the assimilation run (Figs. 2 and 6). The simulation run underestimated the northward wind speed during the early morning of 5 February and failed to resolve the episodic variation in

TABLE 1. Comparison between model-computed and observed wind velocities* at the 10 -m height above the sea surface for 1-14 Feb 1995.

\begin{tabular}{|c|c|c|c|c|c|c|c|c|}
\hline \multirow[b]{3}{*}{ Station } & \multicolumn{4}{|c|}{ Simulation } & \multicolumn{4}{|c|}{ Assimilation } \\
\hline & \multicolumn{2}{|c|}{$u\left(\mathrm{~m} \mathrm{~s}^{-1}\right)$} & \multicolumn{2}{|c|}{$v\left(\mathrm{~m} \mathrm{~s}^{-1}\right)$} & \multicolumn{2}{|c|}{$u\left(\mathrm{~m} \mathrm{~s}^{-1}\right)$} & \multicolumn{2}{|c|}{$v\left(\mathrm{~m} \mathrm{~s}^{-1}\right)$} \\
\hline & $\overline{\overline{|\Delta u|}}$ & $\sigma_{\Delta u}$ & $\overline{\overline{|\Delta v|}}$ & $\sigma_{\Delta v}$ & $\overline{|\Delta u|}$ & $\sigma_{\Delta u}$ & $\overline{\overline{|\Delta v|}}$ & $\sigma_{\Delta v}$ \\
\hline 44005 & 1.56 & 1.95 & 2.20 & 2.74 & 0.96 & 1.14 & 0.72 & 0.89 \\
\hline 44007 & 1.78 & 2.07 & 1.91 & 2.31 & 0.37 & 0.47 & 0.62 & 0.78 \\
\hline 44013 & 2.59 & 3.13 & 4.30 & 4.96 & 0.99 & 1.20 & 1.48 & 1.77 \\
\hline 44025 & 2.33 & 3.01 & 3.44 & 4.15 & 1.04 & 1.26 & 1.48 & 1.76 \\
\hline ALSN6 & 3.34 & 4.33 & 2.24 & 2.94 & 2.15 & 2.63 & 1.03 & 1.36 \\
\hline IOSN3 & 2.68 & 3.54 & 2.81 & 3.38 & 1.49 & 1.89 & 1.01 & 1.23 \\
\hline MDM1 & 2.15 & 2.73 & 2.16 & 2.85 & 1.11 & 1.44 & 0.72 & 0.94 \\
\hline All stations & 2.43 & 3.18 & 2.84 & 3.57 & 1.27 & 1.66 & 1.06 & 1.36 \\
\hline
\end{tabular}

* Note: $\overline{|\Delta u|}$ and $\overline{|\Delta v|}$ are the means of the absolute values of the difference between model-computed and observed $u$ (eastward positive) and $v$ (northward positive) wind components, respectively; $\sigma_{\Delta u}$ and $\sigma_{\Delta v}$ are the standard deviations of $\Delta u$ and $\Delta v$, respectively. 
TABLE 2. Comparison between assimilated and observed wind velocities* at the 10-m height above the sea surface for 1 Jan-30 Jun 1995.

\begin{tabular}{llllll}
\hline \hline & \multicolumn{2}{c}{$u\left(\mathrm{~m} \mathrm{~s}^{-1}\right)$} & & \multicolumn{2}{c}{$v\left(\mathrm{~m} \mathrm{~s}^{-1}\right)$} \\
\cline { 2 - 3 } \multicolumn{1}{c}{ Station } & $\overline{|\Delta u|}$ & $\sigma_{\Delta u}$ & & $\overline{|\Delta v|}$ & $\sigma_{\Delta v}$ \\
\hline 44005 & 0.47 & 0.66 & & 0.56 & 0.70 \\
44007 & 0.40 & 0.52 & & 0.49 & 0.67 \\
44008 & 0.39 & 0.52 & & 0.47 & 0.61 \\
44011 & 0.40 & 0.55 & & 0.54 & 0.71 \\
44013 & 0.62 & 0.82 & & 0.57 & 0.83 \\
44025 & 0.62 & 0.81 & 0.72 & 0.94 \\
ALSN6 & 1.17 & 1.57 & & 1.04 & 1.35 \\
IOSN3 & 0.78 & 1.11 & 0.81 & 1.03 \\
MDM1 & 0.65 & 0.91 & 0.68 & 0.88 \\
All stations & 0.63 & 0.92 & 0.67 & 0.90 \\
\hline
\end{tabular}

* Note: the definitions of $\overline{|\Delta u|}, \overline{|\Delta v|}, \sigma_{\Delta u}$, and $\sigma_{\Delta v}$ as in Table 1 .

wind direction during 5-9 February (Fig. 2). Both errors were minimized by nudging in the assimilation run (Fig. 5). Since this improvement occurred at all buoys, the spatial pattern of the predicted wind field agreed better with the buoy wind pattern in the GoM/GB region. For example, the predicted wind field merged well with the buoy vector winds during the entire 3-9 February period when the cold front passed over GB (Fig. 7). While this result is perhaps not unexpected, since the model surface winds are being nudged toward the buoy winds so that their comparison should be good, Fig. 7 illustrates that the nudging method used in this study is both robust and efficient.

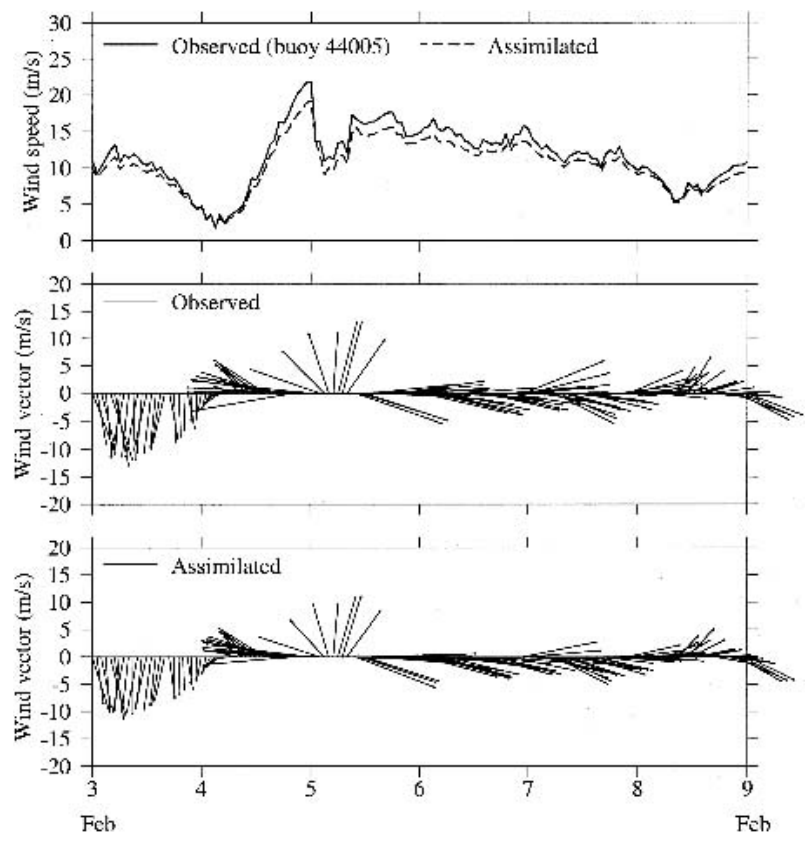

FIG. 6. Comparison of model-assimilated and observed wind speed and wind vectors at a height of $10 \mathrm{~m}$ above the sea surface on buoy 44005 for the 3-9 Feb period. In this case, coastal buoy winds were included in the station nudging data assimilation.
The comparison between simulated and assimilated pressure fields shown in Figs. 3 and 7 indicates that nudging assimilation slightly slowed down the movement of the low pressure center when the cold front entered the GoM from the land, while slightly increasing the pressure value around the center of the pressure low. It is difficult to evaluate this adjustment because there are no observed pressure data available on buoys for comparison. In spite of it, the nudging assimilation seemed to provide a more realistic wind field that is consistent with the observations on those buoys.

On the other hand, the station nudging assimilation approach did not improve the accuracy of the predicted surface heat flux. This is not surprising since the air-sea heat fluxes depend only on wind speed and not wind direction. The primary effect of station nudging in the GoM/GB region is to improve the predicted wind direction. To improve the predicted air-sea heat flux, we made the following modifications to the GoM/GB MM5 PBL model.

\section{Modification of the MM5 heat flux algorithm}

According to the standard Monin-Obukhov similarity theory, the sensible $\left(Q_{h}\right)$ and latent $\left(Q_{e}\right)$ heat fluxes at the sea surface are defined by the equations (A1)(A4) in the appendix. The key parameters that directly affect the accuracy of the heat flux estimation are 1) friction velocity $\left.\left(u_{*}\right), 2\right)$ temperature fluctuation $\left(T_{*}\right)$, and 3 ) water vapor mixing ratio $\left(q_{*}\right)$. The TOGA COARE (TC) heat flux algorithm developed by Fairall et al. (1996) provides estimates of $u_{*}, T_{*}$, and $q_{*}$ (and thus $\tau, Q_{h}$, and $Q_{e}$ ) from bulk measurements of wind speed, air temperature, relative humidity, and barometric pressure made at specified heights above the mean sea surface and the sea surface temperature (see the appendix). Since the bulk sea surface temperature is typically measured at a depth $1 \mathrm{~m}$ below the sea surface and not at the true surface, the TC algorithm can use additional measurements of incident short- and longwave radiation to estimate the true surface temperature, which is typically cooler than the $1-\mathrm{m}$ temperature under low wind conditions. (This "coolskin" correction can be quite important in the Tropics but is less important in midlatitude regions like the GoM/GB region.) The TC algorithm features advanced formulations for surface roughness, vertical profile corrections for stable and unstable conditions, and wind gustiness, which have been well tested against in situ measurements in a number of field experiments.

In this study, we used a slightly modified version of the TC (version 2) algorithm to compute the surface heat fluxes in the MRF scheme. The TC algorithm included gustiness with a minimum wind gust speed of 0.5 $\mathrm{m} \mathrm{s}^{-1}$ in stable conditions, the cool-skin correction was ignored, and the ratio of the measurement height to Monin-Obukhov length was limited to be smaller than 

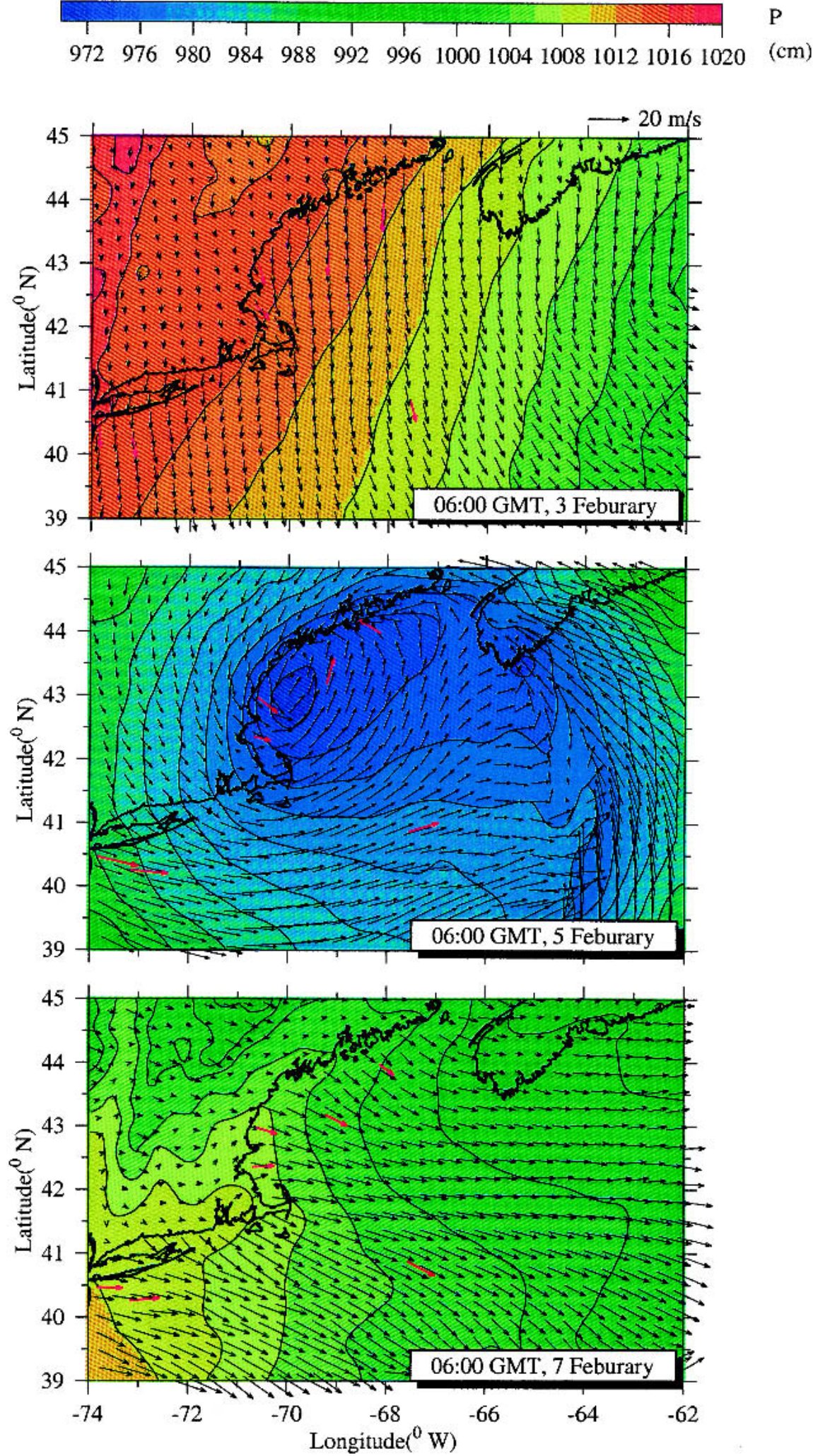

FIG. 7. Model-assimilated 10-m wind vectors (black) and surface air pressure (color contours) at 0600 UTC 3, 5, and $7 \mathrm{Feb} 1995$. The red vectors show the $10-\mathrm{m}$ vector winds measured on the coastal buoys. In this case, coastal buoy wind data were included in the station nudging data assimilation. 
TABLE 3. Comparison between model-computed and observed latent and sensible surface heat fluxes of 5-7 Feb 1995.*

\begin{tabular}{lccccc}
\hline \hline & \multicolumn{2}{c}{$\begin{array}{c}\text { Latent flux } \\
\left(\mathrm{W} \mathrm{m} \mathrm{m}^{-2}\right)\end{array}$} & & \multicolumn{2}{c}{$\begin{array}{c}\text { Sensible flux } \\
\left(\mathrm{W} \mathrm{m} \mathrm{m}^{-2}\right)\end{array}$} \\
\cline { 2 - 3 } \cline { 5 - 6 } \multicolumn{1}{c}{ PBL model } & $\overline{|\Delta Q|}$ & $\sigma_{\Delta q}$ & & $\overline{|\Delta Q|}$ & $\sigma_{\Delta q}$ \\
\hline Blackadar & 141 & 157 & & 200 & 229 \\
ETA & 158 & 189 & & 171 & 208 \\
MRF & 108 & 118 & & 170 & 195 \\
Gayno-Seaman & 69.6 & 76.7 & & 177 & 199 \\
MRF-TC & 26.7 & 34.6 & & 18.0 & 24.6 \\
\hline
\end{tabular}

* Note: $\overline{|\Delta Q|}$ and $\sigma_{\Delta q}$ are the means and standard deviations of the absolute values of the difference between model-computed and observed sea surface heat fluxes components, respectively.

or equal to 1 to ensure convergent nonzero stress and heat flux values for strongly stable conditions [see Pawlowicz et al. (2001) for a full description of the air-sea flux algorithm used here]. The input data for the TC algorithm were taken directly from the MRF PBL model prediction.

The modified MRF-TC PBL model made a significant improvement in the accuracy of the predicted sensible and latent heat fluxes (Tables 3 and 4), especially during the passage of cold fronts. During the 5-7 February example, the agreement between the predicted fluxes and the GLOBEC GB buoy flux estimates is much better (Fig. 8). For this period, the mean differences $^{1}$ (and standard deviations) between predicted buoy sensible and latent fluxes are $170.0 \mathrm{~W} \mathrm{~m}^{-2}( \pm$ 195.0 $\mathrm{W} \mathrm{m}^{-2}$ ) and $108.0 \mathrm{~W} \mathrm{~m}^{-2}\left( \pm 118.0 \mathrm{~W} \mathrm{~m}^{-2}\right)$, respectively, in the simulation case (Fig. 4). With assimilation and the MRF-TC PBL model, the mean differences (and standard deviations) are much less, 18.0 $\mathrm{W} \mathrm{m} \mathrm{m}^{-2}\left( \pm 24.1 \mathrm{~W} \mathrm{~m}^{-2}\right)$ and $26.7 \mathrm{~W} \mathrm{~m}^{-2}( \pm 34.6 \mathrm{~W}$ $\mathrm{m}^{-2}$ ), respectively (Fig. 8 and Table 3 ).

The GoM/GB MM5 with modified MRF-TC PBL model and nudging assimilation was also used to simulate surface winds and heat flux from 1 March to 30 June 1995 after the validation was made for the January-February 1995 experiment. Over the 5-month buoy record, the mean (and standard deviation) of the predicted minus buoy fluxes are $8.9( \pm 14.1) \mathrm{W} \mathrm{m}^{-2}$ for sensible heat flux and $15.4( \pm 22.1) \mathrm{W} \mathrm{m}^{-2}$ for latent heat flux (Fig. 9 and Table 4). This result suggests that the modified MRF-TC PBL model can simulate the sensible and latent fluxes at the sea surface in the GoM/ GB region with a rough accuracy of $10-20 \mathrm{~W} \mathrm{~m}^{-2}$.

\section{Summary}

The fifth-generation PSU-NCAR Mesoscale Model (MM5) has been set up to hindcast the surface forcing over the GoM/GB region. The model uses "two-way

\footnotetext{
1 The mean difference is defined as the absolute value of the difference between model-predicted and observed fluxes.
}

TABLE 4. Comparison between MRF-TC model-computed and observed latent and sensible sea surface heat fluxes for 1 Feb-30 Jun 1995.

\begin{tabular}{ccccc}
\hline \hline \multicolumn{2}{c}{ Latent flux $\left(\mathrm{W} \mathrm{m}^{-2}\right)$} & & \multicolumn{2}{c}{ Sensible flux $\left(\mathrm{W} \mathrm{m}^{-2}\right)$} \\
\cline { 1 - 2 } \cline { 5 - 5 }$\overline{|\Delta Q|}$ & $\sigma_{\Delta q}$ & & $\overline{|\Delta Q|}$ & $\sigma_{\Delta q}$ \\
\hline 15.4 & 22.1 & & 8.9 & 14.1 \\
\hline
\end{tabular}

interaction" nesting between a regional domain covering the eastern United States and Canada and a local domain covering the Mid-Atlantic Bight, GoM/GB, and Scotian Shelf. Hindcasts were conducted for the period 1 January-30 June 1995, and the model results were compared with buoy wind measurements made in the local domain and with surface heat flux time series based on data collected with a WHOI surface mooring deployed on the southern flank of GB. Two types of hindcasts were made, simulation runs without incorporating the buoy wind data and assimilation runs with inclusion of buoy wind data. The simulation experiments showed that MM5 produced roughly the correct wind speed but not wind direction in the GoM/GB region. At the WHOI mooring site, the existing MM5 PBL models predicted roughly the net longwave heat flux at the ocean surface but overestimated the net shortwave heat flux gain and latent and sensible heat flux loses during cold frontal passages.

In the assimilation experiments with station nudging, the MM5-predicted surface wind field agreed better in both wind speed and direction with the buoy wind data, causing the resultant model wind field over the GoM/ GB to be more accurate. To improve the MM5predicted surface air-sea fluxes, the Fairall et al. (1996) air-sea flux algorithm with minor modifications described by Pawlowicz et al. (2001) was added to the MM5 MRF planetary boundary layer model. Assimilation runs made with this modified surface layer model
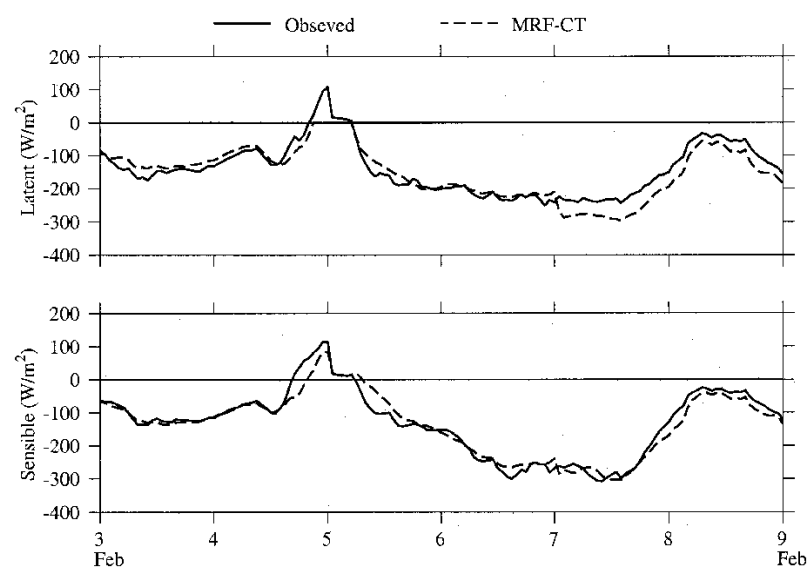

FIG. 8. Comparison of model-predicted and buoy latent and sensible heat fluxes at the GLOBEC buoy site for the 3-9 Feb period. In this case, the MRF-TC PBL model was used. 

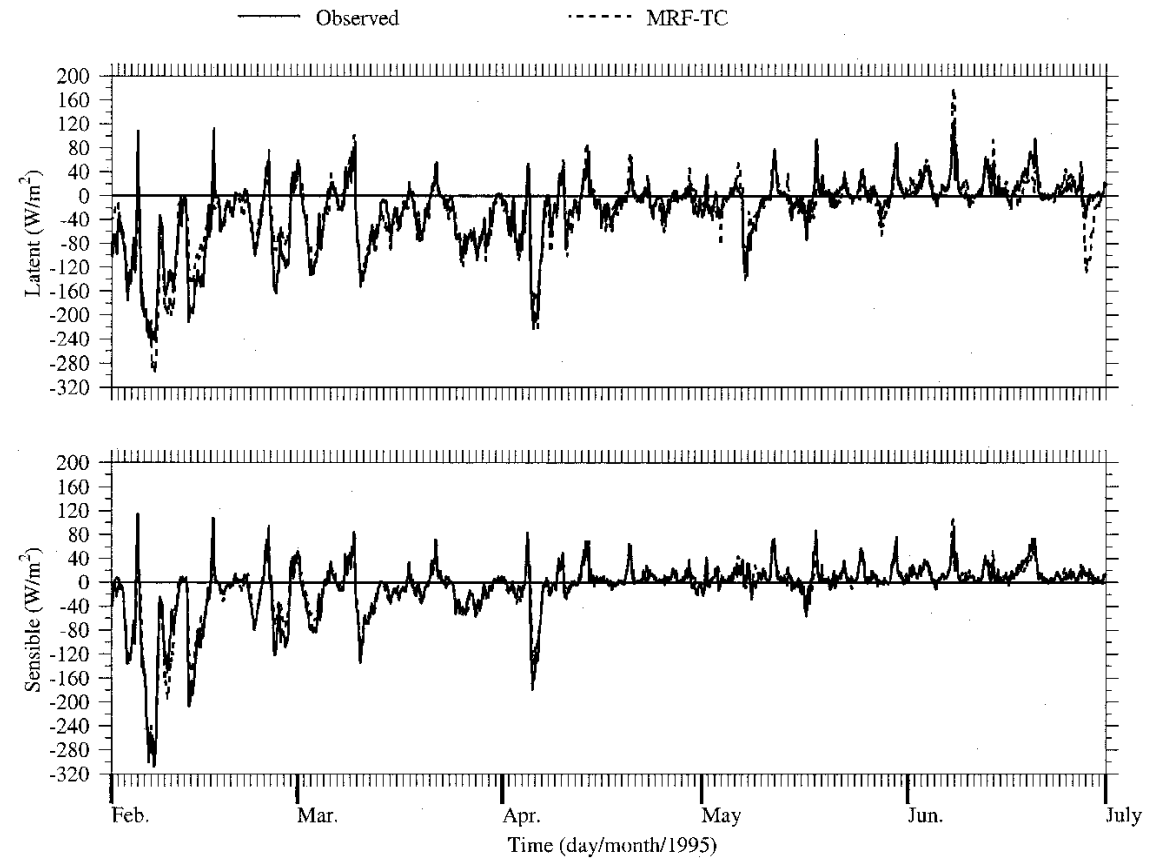

FIG. 9. Comparison of model-predicted and buoy latent and sensible heat fluxes at the GLOBEC buoy site for the 6-month period Jan-Jun 1995. In this case, the MRF-TC PBL model was used.

and the inclusion of daily AVHRR-derived SST produced surface sensible and latent heat flux time series in good agreement with those estimated at the WHOI mooring site in both stable and unstable conditions.

These results suggest that MM5 can be configured to produce accurate surface wind and air-sea fluxes in the GoM/GB region provided that (i) surface winds measured over the ocean in the local domain are assimilated, (ii) accurate daily SST data are used to specify the ocean surface temperature, and (iii) a state-of-theart air-sea flux algorithm like that of Fairall et al. (1996) is used in the MM5 planetary boundary layer model to compute the surface sensible and latent heat fluxes. These results are promising for regional ocean modeling for several reasons. First, they mean that the surface wind stress can be hindcast with sufficient spatial and temporal resolution and accuracy to drive ocean models in realistic (not idealized) simulations. Second, three of the four components of the surface heat flux can be hindcast with reasonable accuracy using the modified MM5 planetary boundary layer model. What remains to be done is to improve the MM5 prediction of the net surface shortwave heat flux. When this is accomplished, then the complete surface mesoscale forcing (i.e., momentum, heat, and moisture fluxes) can be predicted and applied in coastal ocean model studies.

Acknowledgments. This research was supported by the U.S. GLOBEC Northwest Atlantic/Georges Bank program through NSF Grants OCE 02-34545 and OCE
02-27679, NOAA Grant NA 16092323, and NSF CoOP Grant OCE 01-96543 to C. Chen, and NSF Grant OCE 02-27679 to R. C. Beardsley. Song Hu was supported by a SMAST graduate scholarship from NASA Grant NAG 13-02042, and Qichun Xu was supported by Chen's NSF and NOAA grants mentioned above. Huichan Lin was supported by the Georgia DNR Grants 024409-01 and 026450-01.

\section{APPENDIX \\ Description of the TOGA COARE Heat Flux Algorithm}

In Fairall et al. (1996), the TC bulk flux algorithm was built on a standard Monin-Obukhov similarity theory in which sensible $\left(Q_{h}\right)$ and latent $\left(Q_{e}\right)$ heat fluxes at the sea surface are defined by

$$
\begin{gathered}
Q_{h}=\rho_{a} c_{\mathrm{pa}} \overline{w^{\prime} T^{\prime}}=-\rho_{a} c_{\mathrm{pa}} u_{*} T_{*} \quad \text { and } \\
Q_{e}=\rho_{a} L_{e} \overline{w^{\prime} q^{\prime}}=-\rho_{a} L_{e} u_{*} q_{*},
\end{gathered}
$$

where $w^{\prime}, T^{\prime}$, and $q^{\prime}$ are the turbulent fluctuations of vertical air velocity, temperature, and water vapor mixing ratio; $u_{*}, T_{*}$, and $q_{*}$ are the Monin-Obukhov similarity scaling parameters of the friction velocity, temperature fluctuation, and water vapor mixing ratio; $\rho_{a}$ is the density of moist air; $c_{\mathrm{pa}}$ is the specific heat of dry air; and $L_{e}$ is the latent heat of evaporation of water. The definitions of $w^{\prime}, T^{\prime}, \mathrm{q}^{\prime}, u_{*}, T_{*}, q_{*}, \rho_{a}, c_{\mathrm{pa}}$, and $L_{e}$ are 
given in the text. In the ocean, $L_{e}$ is computed using the empirical expression

$$
L_{e}=\left(2.501-0.00237 T_{s}\right) \times 10^{6} \mathrm{~J} \mathrm{~kg}^{-1},
$$

and the relationship between the surface wind stress and $u_{*}$ is given by

$$
\tau=\rho_{a} \overline{w^{\prime} u^{\prime}}=-\rho_{a} u_{*}^{2}
$$

where $u^{\prime}$ is the turbulent fluctuation of the streamwise component of the horizontal wind velocity. The procedures used to estimate key parameters in the TC algorithm are presented here for completeness.

\section{a. Definitions of parameters}

\section{1) Roughness $\left(z_{o}\right)$}

The roughness height is estimated by the formula suggested by Smith (1988):

$$
z_{o}=\alpha \frac{u_{*}^{2}}{g}+0.11 \frac{v}{u_{*}},
$$

where $\alpha$ is the Charnock parameter specified as $0.011, g$ is the gravity given as $9.8 \mathrm{~m} \mathrm{~s}^{-2}$, and $v$ is the temperature-dependent air viscosity, calculated using a thirdorder polynomial in a form of

$$
\begin{aligned}
v= & 1.326 \times 10^{-5}\left(1+6.542 \times 10^{-3} T_{a}+8.301\right. \\
& \left.\times 10^{-6} T_{a}^{2}+4.84 \times 10^{-9} T_{a}\right),
\end{aligned}
$$

where $T_{a}$ is the air temperature $\left({ }^{\circ} \mathrm{C}\right)$ at a measurement height of $z_{t}$. For given values of $\alpha, g$, and $v, z_{o}$ depends only on $u_{*}$.

\section{2) AIR AND SEA SURFACE SPECIFIC HUMIDITY VALUES $\left(q_{a}\right.$ AND $\left.q_{s}\right)$}

The air specific humidity $\left(q_{a}\right)$ and sea surface specific humidity $\left(q_{s}\right)$ are defined as

$$
q_{a}=0.01 h_{r} q_{\mathrm{sat}}\left(T_{a}, P_{a}\right) ; q_{s}=0.98 q_{\mathrm{sat}}\left(T_{s}, P_{a}\right),
$$

where $P_{a}$ and $h_{r}$ are the air pressure and relative humidity measured at height $z_{q}$, respectively; $q_{\text {sat }}\left(T_{a}, P_{a}\right)$ is the saturation specific humidity at $T_{a}$ and $P_{a}$, while $q_{\text {sat }}\left(T_{s}, P_{a}\right)$ is the saturation specific humidity of air in equilibrium with liquid freshwater at the sea surface water temperature $T_{s}$ and $P_{a}$. The factor 0.98 represents the reduction in the saturation specific humidity over seawater due to the ocean salinity. Given the temperature $T\left({ }^{\circ} \mathrm{C}\right)$ and $P_{a}(\mathrm{mb}), q_{\text {sat }}\left(T, P_{a}\right)$ can be determined using the Tetents formula for the saturation vapor pressure (Buck 1981) as follows:

$$
\begin{aligned}
q_{\mathrm{sat}}\left(T, P_{a}\right)= & 1.004 \times 6.112 \times 0.622 e^{17.502 T} / \\
& {\left[P_{a}(240.97+T)\right] . }
\end{aligned}
$$

\section{3) AIR DENSITY $\left(\rho_{a}\right)$}

The air density $\rho_{a}$ depends on the air temperature, relative humidity, and the saturation specific humidity. It is calculated by

$$
\rho_{a}=\frac{100 P_{a}}{287\left(T_{a}+273.16\right)\left(1+0.61 q_{a}\right)} .
$$

\section{4) AIR-SEA DIFFERENCES OF TEMPERATURE AND SPECIFIC HUMIDITY}

The air-sea temperature difference $(\Delta T)$ is defined as

$$
\Delta T=\theta-T_{s},
$$

where $\theta$ is the air potential temperature defined as $\theta=$ $T_{a}+0.0098 z_{t}$. The air-sea specific humidity difference is defined as

$$
\Delta q=q_{a}-q_{s}
$$

\section{5) WIND SPEED AT MEASUREMENT HEIGHT}

The wind speed used in the TC flux calculations is defined as

$$
S_{u}=\sqrt{u_{r}^{2}+w_{g}^{2}},
$$

where $u_{r}$ is the wind speed measured at height $z_{r}$ and $w_{g}$ is the convective scaling velocity. The value of $w_{g}$ depends on the air stability. In the TC code, $w_{g}$ is determined by iteration starting with an initial guess of $0.5 \mathrm{~m} \mathrm{~s}^{-1}$.

\section{6) BulK Richardson NUMBER}

The bulk Richardson number is defined as

$$
\mathrm{Ri}=\frac{g z_{r}\left(\Delta T+0.61 T_{\mathrm{ab}} \Delta q\right)}{T_{\mathrm{ab}} S_{u}^{2}},
$$

where $T_{\mathrm{ab}}$ is the absolute air temperature that is defined as $T_{\mathrm{ab}}=T_{a}+273.16(\mathrm{~K})$.

\section{7) NeUtral SCALING COEFFICIENTS}

At neutral air-sea conditions, the roughness lengths for temperature and humidity $\left(z_{o T}\right.$ and $\left.z_{o q}\right)$ are given as

$$
z_{o T}=z_{o q}=7.5 \times 10^{-5} .
$$

The neutral drag coefficient $C_{\mathrm{dn}}$ is a function of the velocity roughness. According to Smith (1988), $z_{o}$ and $u_{*}$ are unknown variables that depend on each other. An initial guess of $u_{*}$ in neutral conditions is $0.36 \times S_{u}$. Using this initial value, a 10-loop iteration solution of the following two equations,

$$
\left\{\begin{array}{l}
z_{o}=0.011 u_{*}^{2} / g+0.11 v / u_{*} \\
u_{*}=S_{u} \frac{\kappa}{\log \left(z_{r} / z_{o}\right)}
\end{array},\right.
$$


is obtained for $z_{o}$, which then determines $C_{\mathrm{dn}}$ using

$$
C_{\mathrm{dn}}=\frac{\kappa}{\log \left(z_{r} / z_{o}\right)},
$$

where $\kappa=0.4$ is von Kármán's constant. Similarly, $C_{\mathrm{Tn}}$ and $C_{\mathrm{qn}}$ are calculated by

$$
C_{\mathrm{Tn}}=\frac{\kappa}{\log \left(z_{r} / z_{o T}\right)} ; C_{\mathrm{qn}}=\frac{\kappa}{\log \left(z_{r} / z_{o q}\right)} .
$$

When neutral transfer coefficients are estimated, the frictional velocity, temperature, and humidity scaling factors are determined by

$$
\begin{aligned}
& u_{*}=C_{\mathrm{dn}} S_{u} ; T_{*}=C_{\mathrm{Tn}} \Delta T ; q_{*}=C_{\mathrm{qn}} \Delta q ; \\
& T_{v^{*}}=T_{*}\left(1+0.61 q_{a}\right)+0.61 T_{\mathrm{ab}} q_{*} .
\end{aligned}
$$

\section{b. Procedure for estimating $u_{*}, T_{*}$, and $q_{*}$}

In order to calculate accurately the sensible and latent heat fluxes in non-neutral conditions, an iterative approach is used to estimate $u_{*}, T_{*}$, and $q_{*}$, starting with neutral values. The steps are given as follows.

1) Set up an initial value of the roughness based on a neutral value of $u_{*}$ and

$$
z_{o}=\alpha \frac{u_{*}^{2}}{g}+0.11 \frac{v}{u_{*}} .
$$

2) Compute $\xi_{r}=z_{r} / L, \xi_{t}=z_{t} / L, \xi_{q}=z_{q} / L$, where $L$ is the Monin-Obukov length, which is given as

$$
L^{-1}=\frac{g \kappa T_{v^{*}}}{T_{v} u_{*}^{2}}, T_{v}=T_{\mathrm{ab}}\left(1+0.61 q_{a}\right) .
$$

3) Set up an upper limit on $\xi_{r}=z_{r} / L=1$ to force convergence under very stable conditions. In particular,

$$
\xi_{r} \equiv 1.0 \text { if } \xi_{r}=z_{r} / L>1.0 .
$$

The same treatment is also applied to $\xi_{t}=z_{t} / L$ and $\xi_{q}$ $=z_{q} / L$.

4) Determine the turbulent velocity profile function $\Psi_{r}$ for a given $\xi_{r}=z_{r} / L$. This function includes a weighting factor due to Rogers to combine the Dyer and free convection forms for unstable conditions. If $\xi_{r}$ $>0$, then

$$
\Psi_{r}=-4.7 \xi_{r}
$$

if $\xi_{r}<0$ (unstable conditions), the velocity profile function is calculated as follows:

$$
\begin{aligned}
y_{a} & =\sqrt[4]{1-16 \xi_{r}} ; y_{b}=\sqrt[3]{1-12.87 \xi_{r}} \\
\Psi_{a} & =2.0 \log \frac{1+y_{a}}{2}+\log \frac{1+y_{a}^{2}}{2}-2.0 \tan ^{-1} y_{a}+\pi / 2
\end{aligned}
$$

$$
\begin{aligned}
\Psi_{b}= & 1.5 \log \frac{1+y_{b}+y_{b}^{2}}{3}-\sqrt{3} \tan ^{-1} \frac{1+2 y_{b}}{\sqrt{3}} \\
& +\pi / \sqrt{3} .
\end{aligned}
$$

Rogers' weighting factor is given as $F=1 /\left(1+\xi_{r}^{2}\right)$ and in unstable conditions, $\Psi_{r}$ is equal to

$$
\Psi_{r}=F \Psi_{a}+(1-F) \Psi_{b} .
$$

5) Recalculate new $u_{*}$ and Reynolds number $\left(R_{r}\right)$. Considering a correction due to convection, $u_{*}$ is estimated by

$$
u_{*}=S_{u} \frac{\kappa}{\log \left(z_{r} / z_{o}\right)-\Psi_{r}},
$$

and a new Reynolds number is given as

$$
R_{r}=z_{o} u_{*} / v .
$$

6) Calculate Reynolds numbers and roughness for temperature and humidity. The Reynolds numbers for temperature and humidity $\left(R_{t}\right.$ and $\left.R_{q}\right)$ vary with $R_{r}$. They are calculated empirically as follows:

$$
R_{t}= \begin{cases}0.177 & \text { if } R_{r} \leq 0.11 \\ 1.376 R_{r}^{0.929} & \text { if } 0.11<R_{r} \leq 0.825 \\ 1.026 / R_{r}^{0.599} & \text { if } 0.825<R_{r} \leq 3 \\ 1.625 / R_{r}^{1.018} & \text { if } 3<R_{r} \leq 10 \\ 4.661 / R_{r}^{1.475} & \text { if } 10<R_{r} \leq 30 \\ 34.904 / R_{r}^{2.067} & \text { if } 30<R_{r}\end{cases}
$$

and

$$
R_{q}=\left\{\begin{array}{ll}
0.292 & \text { if } R_{r} \leq 0.11 \\
1.808 R_{r}^{0.826} & \text { if } 0.11<R_{r} \leq 0.825 \\
1.393 / R_{r}^{0.528} & \text { if } 0.825<R_{r} \leq 3 \\
1.956 / R_{r}^{0.87} & \text { if } 3<R_{r} \leq 10 \\
4.994 / R_{r}^{1.297} & \text { if } 10<R_{r} \leq 30 \\
30.79 / R_{r}^{1.846} & \text { if } 30<R_{r}
\end{array} .\right.
$$

Once $R_{t}$ and $R_{q}$ are determined, the roughness values for temperature and humidity can be updated by

$$
z_{o T}=v R_{t} / u_{*} ; z_{o q}=v R_{q} / u_{*} \cdot
$$

7) Calculate the stability functions of $\Psi_{t}$ and $\Psi_{q}$. These two functions can be determined using a similar method for $\Psi_{r}$. For example, if $\xi_{t}>0$,

$$
\Psi_{t}=-4.7 \xi_{t}
$$

if $\xi_{t}<0$ (unstable conditions), they are calculated as follows:

$$
y_{a}=\sqrt[4]{1-16 \xi_{t}} ; y_{b}=\sqrt[3]{1-12.87 \xi_{t}},
$$




$$
\begin{aligned}
\Psi_{a}= & 2.0 \log \frac{1+y_{a}^{2}}{2}, \Psi_{b}=1.5 \log \frac{1+y_{b}+y_{b}^{2}}{3} \\
& -\sqrt{3} \tan ^{-1} \frac{1+2 y_{b}}{\sqrt{3}}+\pi / \sqrt{3} .
\end{aligned}
$$

Roger's weighting factor is given as $F=1 /\left(1+\xi_{t}^{2}\right)$. In unstable conditions, $\Psi_{t}$ is given as

$$
\Psi_{t}=F \Psi_{a}+(1-F) \Psi_{b} .
$$

Replacing $\xi_{t}$ by $\xi q$, the value of $\Psi q$ in stable and unstable conditions can be calculated using the same formula, (A33)-(A35).

8) Calculate new transfer coefficients $C_{T}$ and $C_{q}$ at the measurement heights of $z_{t}$ and $z_{q}$. After the stability functions for temperature and humidity are determined, $C_{T}$ and $C_{q}$ can be updated by

$$
C_{T}=\frac{\kappa}{\log \left(z_{r} / z_{o T}\right)-\Psi_{t}} ; C_{q}=\frac{\kappa}{\log \left(z_{r} / z_{o q}\right)-\Psi_{q}} .
$$

9) Compute new values of $T_{*}, q_{*}$, and $T_{\nu^{*}}$. They are equal to

$$
\begin{aligned}
T_{*} & =C_{T} \Delta T ; q_{*}=C_{q} \Delta q ; \\
T_{\nu *} & =T_{*}\left(1+0.61 q_{a}\right)+0.61 T_{\mathrm{ab}} q_{*} .
\end{aligned}
$$

10) Estimate new gustiness. Assume that the minimum value of $w_{g}$ under all conditions is $0.5 \mathrm{~m} \mathrm{~s}^{-1}$. For unstable conditions with $\xi r<0$,

$$
w_{g}=-1.2\left(650 g u_{*} T_{v *} / T_{\mathrm{ab}}\right)^{1 / 3},
$$

and

$$
S_{u}=\sqrt{u_{r}^{2}+w_{g}^{2}}
$$

Steps 1-10 are repeated 20 times to ensure convergence in all conditions. After these iterations, the updated wind stress and sensible and latent heat fluxes are given as

$$
\begin{aligned}
& \tau_{s}=\rho_{a} u_{*}^{2} ; Q_{h}=-\rho_{a} c_{\mathrm{pa}} u_{*} T_{*} ; Q_{e}=-\rho_{a} L_{e} u_{*} q_{*} ; \\
& L=z_{r} / \xi_{r} .
\end{aligned}
$$

In addition, the updated transfer coefficients $C_{d}, C_{T}$, and $C_{q}$ at measurement heights are given as

$$
C_{d}=\left(u_{*} / \Delta u\right)^{2} ; C_{T}=u_{*} T_{*} /(\Delta u \Delta T) ; C_{q}=u_{*} q_{*} /(\Delta u \Delta q) .
$$

\section{REFERENCES}

Anthes, R. A., and T. T. Warner, 1978: Development of hydrodynamic models suitable for air pollution and other mesometeorological studies. Mon. Wea. Rev., 106, 1045-1078.

Beardsley, R. C., S. J. Lentz, R. A. Weller, R. Limburner, J. D. Irish, and J. B. Edson, 2003: Surface forcing on the southern flank of Georges Bank, February-August 1995. J. Geophy. Res., 108, 8007, doi:10.1029/2002JC001359.
Betts, A. K., and M. J. Miller, 1986: A new convective adjustment scheme. Part II: Single column tests using GATE wave, BOMEX, ATEX and Artic air-mass data sets. Quart. J. Roy. Meteor. Soc., 112, 693-709.

Blackadar, A. K., 1976: Modeling the nocturnal boundary layer. Preprints, Third Symp. on Atmospheric Turbulence and Air Quality, Raleigh, NC, Amer. Meteor. Soc., 46-49.

_ 1979: High resolution models of the planetary boundary layer. Advances in Environmental Science and Engineering, J. Pfafflin and E. Ziegler, Eds., Vol. 1, Gordon and Breach, $50-85$.

Braun, S. A., and W. K. Tao, 2000: Sensitivity of high-resolution simulations of hurricane Bob (1991) to planetary boundary layer parameterization. Mon. Wea. Rev., 128, 3941-3961.

Buck, A. L., 1981: New equations for computing vapor pressure and enhancement factor. J. Appl. Meteor., 20, 1527-1532.

Burk, S. D., and W. T. Thompson, 1989: A vertically nested regional numerical prediction model with second-order closure physics. Mon. Wea. Rev., 117, 2305-2324.

Dudhia, J., 1993: A nonhydrostatic version of the Penn State/ NCAR mesoscale model: Validation tests and simulation of an Atlantic cyclone and cold front. Mon. Wea. Rev., 121, 1493-1513.

- D. Gill, K. Manning, W. Wang, C. Bruyere, J. Wilson, and S. Kelly, 2003: PSU/NCAR mesoscale modeling system tutorial class notes and user's guide. MM5 modeling system version 3, Mesoscale and Microscale Meteorology Division, National Center for Atmospheric Research, 390 pp.

Fairall, C. W., E. F. Bradley, D. P. Rogers, J. B. Edson, and G. S. Young, 1996: Bulk parameterization of air-sea fluxes for Tropical Ocean Global Atmosphere Coupled OceanAtmosphere Response Experiment. J. Geophys. Res., 101 (C2), 3747-3764.

Genon, L. M., 1987: Numerical simulation of a fog event with a one-dimensional boundary layer model. Mon. Wea. Rev., 115, 592-607.

Grell, G. A., 1993: Prognostic evaluation of assumptions used by cumulus parameterizations. Mon. Wea. Rev., 121, 764-787.

—, J. Dudhia, and D. R. Stauffer, 1994: A description of the Fifth-Generation Penn State/NCAR Mesoscale Model (MM5). NCAR Tech. Note NCAR/TN 398+STR, 117 pp.

Holtslag, A. A. M., and F. T. M. Nieuwstadt, 1986: Scaling the atmospheric boundary layer. Bound.-Layer Meteor., 36, 201209.

Hong, S. Y., and H.-L. Pan, 1996: Nonlocal boundary layer vertical diffusion in a medium-range forecast model. Mon. Wea. Rev., 124, 2322-2339.

Jacquemin, B., and J. Noilhan, 1990: Sensitivity study of a land surface parameterization using the HAPEX-MOBILHY dataset. Bound.-Layer Meteor., 52, 93-134.

Janjic, I. J., 1994: The step-mountain ETA coordinate model: Further developments of the convection, viscous sublayer, and turbulence closure schemes. Mon. Wea. Rev., 122, 927-945.

Mellor, G. L., and T. Yamada, 1974: A hierarchy of turbulence closure models for planetary boundary layers. J. Atmos. Sci., 33, 1791-1806.

- and - 1982: Development of a turbulence closure model for geophysical fluid problem. Rev. Geophys. Space Phys., 20, 851-875.

Noilhan, J., and S. Planton, 1989: A simple parameterization of land surface processes for meteorological models. Mon. Wea. Rev., 117, 536-549.

Pawlowicz, R., R. Beardsley, S. Lentz, E. Dever, and A. Anis, 2001: The Air-Sea Toolbox: Boundary-layer parameterization for everyone. Eos, Trans. Amer. Geophys. Union, 84 (1), 2.

Pleim, J. E., and J. S. Chang, 1992: A non-local closure model for vertical mixing in the convective boundary layer. Atmos. Environ., 26A, 965-981. 
—, and A. Xiu, 1995: Development and testing of a surface flux and planetary boundary layer model for application in mesoscale models. J. Appl. Meteor., 34, 16-32.

Smith, S. D., 1988: Coefficients for sea surface wind stress, heat flux, and wind profiles as a function of wind speed and temperature. J. Geophys. Res., 93, 15 467-15 472.

Troen, I., and L. Mahrt, 1986: A simple model of the atmospheric boundary layer: Sensitivity to surface evaporation. Bound.Layer Meteor., 37, 107-128.

Webster, P. J., and R. Lukas, 1992: TOGA COARE: The Coupled Ocean-Atmosphere Response Experiment. Bull. Amer. Meteor. Soc., 73, 1377-1416.

Zhang, D.-L., and R. A. Anthes, 1982: A high-resolution model of the planetary boundary layer-Sensitivity tests and com- parisons with SESAME-79 data. J. Appl. Meteor., 21, 15941609.

, and X. Wang, 2003: Dependence of hurricane intensity and structures on vertical resolution and time-step size. $A d v$. Atmos. Sci., 20, 711-725.

_ , and W.-Z. Zheng, 2004: Diurnal cycles of surface winds and temperatures as simulated by five boundary layer parameterizations. J. Appl. Meteor., 43, 157-169.

- H.-R. Chang, N. L. Seaman, T. T. Warner, and J. M. Fritsch, 1986: A two-way interactive procedure with terrain resolution. Mon. Wea. Rev., 114, 1330-1339.

Zou, X., Y.-H. Kuo, and Y.-R. Guo, 1995: Assimilation of atmospheric radio refractivity using a nonhydrostatic adjoint model. Mon. Wea. Rev., 123, 2229-2249. 